\title{
ESTUDO COMPARATIVO DOS PERFIS ELETROFORÉTICOS DAS PROTEINAS DOS LIQUIDOS DE CISTOS DE ASTROCITOMAS E DE GLIOBLASTOMAS MULTIFORMES
}

\author{
A. SPINA-FrançA *
}

Rolando A. TENUTO *

A. GaMA DA ROCHA **

O perfil eletroforético das proteínas de líquido de cistos de tumores intracranianos (LCT) nem sempre coincide com aquêle das proteínas do sôro sangüíneo ${ }^{1}$ (sôro) dos respectivos pacientes, embora a maior parte das proteínas de tais líquidos císticos pareça provir do sangue por transudação ao nivel das paredes dos vasos que irrigam o tumor. Esta transudação obedeceria aos mesmos mecanismos observados em outros órgãos e tecidos, mas a ausência de rêde linfática no parênquima nervoso - própria às estruturas de origem ectoblástica - dificultaria a reabsorção do líquido intersticial acumulado ao nivel do tumor, facilitando, portanto, a formação de coleções císticas. Gardner e col. ${ }^{2}$ desenvolveram essas idéias mediante o estudo comparativo do proteinograma do LCT, do líquido cefalorraqueano e do sôro de uma série de pacientes.

Esses autores explicaram as diferenças na composição protêica do LCT pelo balanço entre vários fatôres que interferem na transudação e/ou na reabsorção ao nível do tumor. Entre êles salientam os dependentes da linhagem embrionária do tecido que deu origem à neoplasia e da maior ou menor participação na estrutura desta última de elementos de linhagem mesodérmica oriundos dos capilares de neoformação. Êsses dados são utilizados também para a classificação histopatológica do tumor e para a avaliação do seu grau de malignidade ${ }^{3}$, o que explica, em parte, a concordância entre o diagnóstico histopatológico e aquêle sugerido pela composição química do $\operatorname{LCT}^{4,6}$.

Considerando as diversas hipóteses aventadas por essas pesquisas, foram analisadas, neste estudo, as diferenças entre os perfis protêicos do LCT de dois grupos de tumores da mesma linhagem embrionária, mas com grau de malignidade diferente (astrocitomas e glioblastomas multiformes), tomando como têrmo de comparação os perfis protêicos de coleções cisticas em relação às quais o fator neoplásico estivesse presente (craniofaringeomas) ou não (coleções subdurais de origem inflamatória).

Trabalho da Clínica Neurológica da Fac. Med. da Univ. São Paulo (Prof. A. Tolosa): *Docente Livre; ** Médico estagiário. 


\section{MATERIAL E MÉTODOS}

Foram estudados os perfis protèicos do LCT de 13 astrocitomas (casos 1 a 13) e de 10 glioblastomas multiformes (casos 14 a 23) em comparação àqueles de 7 craniofaringeomas (casos 24 a 30 ) e de 12 líquidos de coleções subdurais de origem inflamatória (casos 31 a 42). O diagnóstico do tipo do tưmor foi baseado em exame histopatológico.

Os perfis protêicos foram estudados mediante eletroforese em papel, segundo técnica anteriormente descrita ${ }^{j}$; o elevado teor protêico total das amostras tornou desnecessária sua concentração prévia.

Atendendo à finalidade do estudo, a participação da albumina no perfil protêico do LCT foi considerada igual à unidade, em funçāo do que, em cada caso, foram calculados os indices correspondentes à participaçāo das diversas globulinas no perfil. Para isto a percentagem correspondente a cada globulina foi dividida pela da albumina no mesmo caso. Os valôres assim obtidos foram grupados segundo as 4 séries de casos, sendo calculadas a média e o desvio padrão respectivos. A comparação das estimativas obtidas foi feita por meio do teste $t$, sendo referidos os resultados significativos (probabilidades entre 5 e $1 \%$ ) e altamente significativos (probabilidade inferior a $1 \%$ ).

\section{RESULTADOS}

Na tabela 1 são apresentados valôres de percentagem de cada fracão no perfil protêico dos liquidos estudados. Na tabela 2 estão reunidas as estimativas que representam os indices de participação de cada globulina no perfil dêsses líquidos segundo as séries de casos estudados.

Em relação às estimativas obtidas para as globulinas dos líquidos de coleções subdurais as diferenças observadas mostraram-se: significativas quanto à menor participaçāo das globulinas alfa-1 e alfa-2 nos astrocitomas e quanto à maior participaçāo da globulina alfa-2 nos glioblastomas $(t=-2,78,-2,40$ e 2,75 , respectivamente); altamente significativas para a maior participação da globulina gama nos glioblastomas e nos craniofaringeomas $(t=3,13$ e 3,03, respectivamente). Em relação às estimativas da série de cranifaringeomas foram significativas as diferenças quanto à menor participação das globulinas alfa-2 e gama nos astrocitomas ( $t=-2,43$ e $-2,11$, respectivamente). A comparação das estimativas referentes aos astrocitomas $\mathrm{e}$ aos glioblastomas multiformes mostraram diferenças altamente significativas quanto à maior participação das globulinas alfa-1 e alfa-2 nos glioblastomas $(t=3,12$ e 5,00 , respectivamente).

\section{COMENTARIOS}

A percentagem de albumina no perfil protêico de um LCT é freqüentemente maior que a do sôro do mesmo paciente; isto não impede que a sua participação no perfil protêico do LCT seja representada pela unidade, pois essa fração provém do sangue por transudação. A participação de cada uma das globulinas no perfil protêico do LCT depende dêsse mesmo fator, mas não se pode excluir, pelo menos em parte, o papel desempenhado por fatôres ligados a aspectos metabólicos das células neoplásicas circunvizinhas ${ }^{2}$. A influência dêstes últimos fatôres não pode ser aventada em relação às proteínas das coleções subdurais de origem inflamatória, motivo pelo qual as estimativas da participação das globulinas nesses líquidos serviram de têrmo de comparação para aquelas dos LCT. Na interpretação dos resultados obtidos foi dado valor apenas às diferenças altamente significativas, considerando o número relativamente pequeno de casos em cada série e a natureza dos números submetidos a análise. 


\begin{tabular}{|c|c|c|c|c|c|}
\hline \multirow[t]{3}{*}{ Caso } & \multicolumn{5}{|c|}{ Fraçōes } \\
\hline & \multirow[t]{2}{*}{ Albumina } & \multicolumn{4}{|c|}{ Globulinas } \\
\hline & & $\alpha_{1}$ & $\alpha_{2}$ & $\beta$ & $\gamma$ \\
\hline 1 & 55,0 & 3,5 & 7,5 & 12,5 & 21,5 \\
\hline 2 & 68,0 & 2,6 & 2,7 & 12,2 & 14,5 \\
\hline 3 & 65,0 & 2,7 & 6,3 & 16,0 & 10,0 \\
\hline 4 & 65,5 & 2,0 & 4,0 & 12,0 & 16,5 \\
\hline 5 & 65,5 & 4,0 & 4,5 & 10,5 & 15,5 \\
\hline 6 & 65,0 & 2,0 & 3,6 & 13,0 & 16,4 \\
\hline 7 & 56,0 & 5,7 & 6,2 & 11,3 & 20,8 \\
\hline 8 & 60,0 & 4,5 & 5,0 & 13,5 & 17,0 \\
\hline 9 & 68,0 & 2,6 & 6,0 & 10,4 & 13,0 \\
\hline 10 & 62,4 & 4,1 & 7,1 & 10,2 & 16,2 \\
\hline 11 & 49,2 & 6,5 & 8,6 & 15,2 & 20,5 \\
\hline 12 & 71,0 & 4,0 & 3,5 & 10,0 & 11,5 \\
\hline 13 & 44,5 & 6,2 & 7,0 & 16,7 & 25,6 \\
\hline 14 & 56,2 & 4,3 & 7,5 & 11,3 & 20,7 \\
\hline 15 & 58,0 & 7,0 & 7,5 & 10,0 & 17,5 \\
\hline 16 & 40,0 & 6,5 & 15,5 & 13,0 & 25,0 \\
\hline 17 & 56,0 & 7,8 & 6,0 & 11,2 & 19,0 \\
\hline 18 & 43,0 & 8,7 & 7,2 & 10,0 & 31,0 \\
\hline 19 & 56,5 & 5,0 & 10,5 & 11,5 & 16,5 \\
\hline 20 & 61,4 & 4,9 & 6,8 & 13,1 & 13,8 \\
\hline 21 & 53,0 & 4,0 & 14,5 & 11,0 & 17,5 \\
\hline 22 & 46,9 & 7,6 & 6,3 & 12,2 & 27,0 \\
\hline 23 & 55,0 & 5,1 & 6,5 & 12,0 & 21,0 \\
\hline 24 & 46,0 & 4,3 & 9,2 & 10,5 & 30,0 \\
\hline 25 & 45,0 & 3,0 & 7,3 & 19,0 & 25,7 \\
\hline 26 & 51,6 & 3,6 & 7,3 & 16,3 & 21,2 \\
\hline 27 & 58,2 & 2,8 & 7,4 & 8,6 & 23,0 \\
\hline 28 & 53,0 & 2,0 & 3,0 & 12,5 & 29,5 \\
\hline 29 & 44,9 & 6,7 & 14,0 & 16,8 & 17,6 \\
\hline 30 & 62,0 & 9,0 & 13,0 & 8,0 & 8,0 \\
\hline 31 & 73,0 & 2,4 & 4,0 & 11,0 & 8.7 \\
\hline 32 & 52,0 & 5,5 & 9,0 & 17,5 & 16,0 \\
\hline 33 & 63,0 & 5,0 & 7,0 & 17,0 & 8,0 \\
\hline 34 & 46,4 & 5,7 & 10,3 & 21,0 & 16,6 \\
\hline 35 & 48,0 & 6,0 & 8,5 & 15,5 & 22,0 \\
\hline 36 & 51,0 & 9,0 & 11,0 & 12,0 & 17,0 \\
\hline 37 & 61,5 & 10,5 & 7,5 & 12,5 & 8,0 \\
\hline 38 & 61,0 & 10,0 & 7,5 & 16,0 & 5,5 \\
\hline 39 & 61,5 & 12,5 & 7,5 & 11,5 & 7,0 \\
\hline 40 & 62,9 & 4,3 & 4,6 & 16,2 & 9,4 \\
\hline 41 & 59,0 & 4,5 & 7,0 & 11,0 & 18,0 \\
\hline 42 & 67,0 & 5,5 & 4,7 & 12,0 & 10,4 \\
\hline
\end{tabular}

Tabela 1 - Percentagens das frações protêicas nos líquidos de cistos em astrocitomas (casos 1 a 13), glioblastomas (casos 14 a 23) e craniofaringeomas (casos 24 a 30), e de coleçōes subdurais (casos 31 a 42). 


\begin{tabular}{|c|c|c|c|c|c|c|c|c|}
\hline \multirow[t]{2}{*}{ Material. } & \multicolumn{8}{|c|}{ Globulinas } \\
\hline & $n_{1}$ & & $\alpha_{2}$ & & f & & $\gamma$ & \\
\hline \multirow[t]{2}{*}{ Astrocitomas } & $\overline{\mathrm{x}} \quad 0,067$ & & 0,095 & & 0,212 & & 0,289 & \\
\hline & s.d. & 0,036 & & 0,042 & & 0,067 & & 0,119 \\
\hline \multirow[t]{2}{*}{ Glioblastomas } & $\bar{x} \quad 0,120$ & & 0,175 & & 0,223 & & 0,416 & \\
\hline & s.d. & 0,043 & & $0,03 \gamma$ & & 0,042 & & 0,165 \\
\hline \multirow[t]{2}{*}{ Craniofaringeomas } & $\overline{\mathrm{x}} \quad 0,087$ & & 0,185 & & 0,285 & & 0,443 & \\
\hline & s.d. & 0,044 & & 0,092 & & 0,111 & & 0,172 \\
\hline \multirow[t]{2}{*}{ Colesōes subdurais } & $\bar{x} \quad 0,117$ & & 0,131 & & 0,251 & & 0,219 & \\
\hline & s.d. & 0,052 & & 0,033 & & 0,085 & & 0,124 \\
\hline
\end{tabular}

Tabela 2 - Média $(\bar{x})$ e desvio padrão (s.d.) dos indices de participacão de cada globulina no perfil protêico dos líquidos de cistos em astrocitomas (19 casos), glioblastomas (10 casos) e craniofaringeomas $(\gamma$ casos), $e$ de colecões subdurais (12 casos).

A maior participação da globulina gama no LC'T de glioblastomas tanto poderia depender de transtornos dos fenômenos de transudação e/ou reabsorção, como estar na dependência de aspectos metabólicos peculiares às suas células neoplásicas. No entanto, contrapõe-se a esta última hipótese, o fato de ter sido encontrada possibilidade também elevada para a participação dessa globulina no LCT de cranifaringeomas, tumores cujo grau de malignidade é pequeno, quando comparado aos dos glioblastomas. Por outro lado, não se pode excluir a influência dos fatôres ligados aos fenômenos de transudação e reabsorção que, nos glioblastomas e nos craniofaringeomas, são aproximadamente semelhantes. Assim, no glioblastoma, novos capilares se formam a partir de brotos do endotélio vascular; a partir da adventícia dêsses vasos há proliferação de tecido conjuntivo que pode substituir áreas necróticas do tumor. Assim sendo, as relações entre o tumor e sua cavidade cística não são uniformes, não se podendo negar que existam áreas em que o contato entre o líquido do cisto e o tecido conjuntivo seja maior. Dessa forma as trocas entre o sangue e o LCT se fariam de modo tal que o perfil protêico dêste último poderia aproximar-se do de LCT de craniofaringeomas, nos quais a parede do cisto é também constituida por tecido conjuntivo e pelas células epiteliais características ${ }^{3}$.

Nos astrocitomas a participação da globulina alfa-1 e da alfa-2 foi menor que a encontrada para as coleções subdurais e para os glioblastomas. Em relação a êstes últimos as diferenças mostraram-se altamente significativas. Essas semelhanças poderiam decorrer da maior intensidade dos fenômenos metabólicos das células neoplásicas do glioblastoma ${ }^{2}$, especialmente no que se refere à globulina alfa-2 (ocorrência de alfa-2 macroglobulinas), porém elas podem ser melhor explicadas pelo tipo de relação existente entre 
o LCT e a cápsula que o circunscreve ${ }^{3}$. Ao contrário do que ocorre nos glioblastomas, nos astrocitomas as paredes dos cistos dificultam as trocas entre o sangue e o LCT, prejudicando a passagem de proteínas de pêso molecular elevado, porque sua estrutura é uniforme, sendo representada quase que sòmente pelos elementos celulares de origem ctoblástica que caracterizam o tumor. Além disso, nos astrocitomas a rêde vascular é pobre e freqüentemente ocorre espessamento das paredes dos vasos por proliferação endotelial, fatôres que também dificultam as trocas entre o sangue e o LCT.

\section{RESUMO}

Foram analisados os perfis eletroforéticos das proteinas dos liquidos contidos em cistos de astrocitoma (13 casos) e de glioblastoma multiforme (10 casos), sendo os resultados comparados àqueles obtidos nos líquidos de cistos de craniofariogeoma ( 7 casos) e de coleções subdurais de origem inflamatória (12 casos). Considerando a participação da albumina no perfil protêico eqüivalente à unidade, foi calculada a participação de cada globulina segundo os grupos de casos.

Em relação aos dados obtidos para as coleçōes subdurais, foi verificado que nos LCT de glioblastomas multiformes era maior a participação da globulina gama, comparável à encontrada no LCT de craniofaringeomas e que, nos LCT de astrocitomas, era menor a participação das globulinas alfa-1 e alfa-2. Esta última verificação se mostrou altamente significativa quando comparada à participação dessas globulinas no LCT de astrocitomas e de glioblastomas.

Os dados obtidos foram discutidos, permitindo atribuir as diferenças encontradas especialmente a fatôres locais, relacionados à diferente constituição das paredes dos cistos nos astrocitomas e nos glioblastomas multiformes.

\section{SUMMARY}

Comparative study of protein fractions from cyst fluids of astrocytoma and glioblastoma multiforme

The differences in the protein composition of cyst fluids from tumors of the central nervous system have been explained by the conditions in which the exchanges between the blood and the cyst fluid occur as well by metabolic aspects related to the malignancy of the tumor cells. In order to explore the influence of these factors the protein fractions from cyst fluids of astrocytoma (13 cases) and from glioblastoma multiforme (10 cases) were studied and the results were compared to those obtained for the protein fractions of two other series of cases: the first was represented by the results obtained for protein fractions of cyst fluids from craneopharyngeoma ( 7 cases) and, the second, by those concerning to the fluids from inflammatory subdural collections (12 cases). 
The protein fractions were studied by paper electrophoresis and the results are presented in table 1 . The participation of each globulin fraction was calculated and the unit for comparison was the percent value of the albumin fraction for each given case and the mean values and their standard deviations are presented in table 2.

The data were discussed and it was possible to show that the differences found are more able to be explained on the basis of the conditions in which the protein exchanges between blood and cyst fluid occur possibly related to the structural characteristics of the wall of the cysts.

\section{REFERENCIAS}

1. CUMINGS, J. N. - The examination of the cerebrospinal fluid and cerebral cyst fluid by paper strip electrophoresis. J. Neurol, Neurosurg. a. Psychiat. 16: 152-157, 1953. 2. GARDNER, W. J.; COLLIS Jr., J. S. \& LEWIS, L. A. - Cystic brain tumors and the blood brain barrier. Arch. Neurol. (Chicago) 8:291-295, 1963. 3. KERNOHAN, J. W. \& SAYRE, G. P. - Tumors of the central nervous system. Armed Forces Institute of Pathology, Washington, 1952. 4. SPINA-FRANÇA, A. Eletroforese em papel das proteínas de líquidos císticos de tumores do sistema nervoso central. Arq. Neuro-Psiquiat. (São Paulo) 16:193-200, 1958. 5. SPINA-FRANCA, A. - Eletroforese das protelnas do liquido cefalorraqueano: técnica. Arq. Neuro-Psiquiat. (São Paulo) 16:236-242, 1958. 6. SZLTWOWSKI, H. B. \& CUMINGS, J. N. - The diagnostic value of chemical examination of cerebral cyst fluids. Brain 84:204-211, 1961 .

Clínica Neurológica - Faculdade de Medicina da Universidade de São Paulo - Caixa Postal 3461 - Săo Paulo, SP - Brasil. 